\title{
Direct sequencing and amplification refractory mutation system for epidermal growth factor receptor mutations in patients with non-small cell lung cancer
}

\author{
HUILI CHU $^{1 *}$, CHEN ZHONG $^{1 *}$, GUOLIANG XUE $^{1}$, XIUJU LIANG $^{1}$, JUN WANG $^{1}$, \\ YINGXIN LIU $^{1}$, SHIWEI ZHAO ${ }^{1}$, QIAN ZHOU ${ }^{2}$ and JINGWANG BI ${ }^{1}$ \\ ${ }^{1}$ Department of Oncology, General Hospital, Jinan Command of the People's Liberation Army, Jinan, \\ Shandong 250031; ${ }^{2}$ Department of Radiology, Jinan Central Hospital, Jinan, Shandong 250014, P.R. China
}

Received June 24, 2013; Accepted August 9, 2013

DOI: 10.3892/or.2013.2709

\begin{abstract}
Treatment with epidermal growth factor receptor (EGFR) tyrosine inhibitors (EGFR-TKIs) provides encouraging outcomes for advanced non-small cell lung cancer (NSCLC) patients with EGFR mutations. Pleural effusion is a common complication of NSCLC. We compared direct DNA sequencing and ADx Amplification Refractory Mutation System (ADx-ARMS) to detect EGFR mutations in malignant pleural effusion samples. We obtained 24 samples from pleural effusion fluid of NSCLC patients. Three common types of EGFR mutations were examined by direct sequencing and ADx-ARMS analysis. The sensitivity of the methods was compared and the relationship between EGFR mutations and response rates of the patients determined. In 14/24 patients, we detected EGFR mutations (58.3\%) by ADx-ARMS, and in 10 samples $(41.7 \%)$ by direct sequencing. In 6 samples, EGFR mutations were on exon 19, and in 8 samples, mutations were on exon 21 by ADx-ARMS. By contrast, we found EGFR mutations in 4 samples on exon 19, and in 6 samples on exon 21 by direct sequencing. Neither method showed mutations on exon 20. Among the 24 patients, there was $83.3 \%$ concordance for the methods. In 18/24 patients, gefitinib treatment was administered, including 10 patients with mutations who showed improved response compared to 8 of the wild-type patients $(\mathrm{P}<0.05)$. In conclusion, EGFR mutation analysis by ADx-ARMS was the most sensitive compared to direct sequencing, and provided more reliable EGFR mutation
\end{abstract}

Correspondence to: Professor Jingwang Bi, Department of Oncology, General Hospital, Jinan Command of the People's Liberation Army, 25 Shifan Street, Jinan, Tianqiao, Shandong 250031, P.R. China

E-mail: jingwangbi@live.cn

*Contributed equally

Key words: EGFR mutation, malignant pleural effusion, direct sequencing, ADx-ARMS, non-small cell lung cancer assessments. ADx-ARMS could be introduced into the clinical practice to identify NSCLC patients likely to benefit from TKI treatment, especially those with malignant pleural effusion.

\section{Introduction}

Lung cancer is the leading cause of cancer-related deaths worldwide, and especially in China. The majority of these deaths are due to non-small cell lung cancer (NSCLC), which is the most common histologic type of lung cancer (1). It is current practice to treat advanced NSCLC with platinum based chemotherapy, although treatment outcomes are particularly poor $(2,3)$. Therefore, target therapy for patients with advanced NSCLC are currently being evaluated.

The epidermal growth factor receptor $(E G F R)$ is a receptor tyrosine kinase (TK) that is frequently overexpressed and plays a central role in the development of NSCLC $(4,5)$. Abnormal activation of EGFR can promote tumor cell proliferation, differentiation and migration. EGFR tyrosine kinase inhibitors (EGFR-TKIs), such as gefitinib and erlotinib, which target $E G F R$, have demonstrated promising outcomes in the treatment of NSCLC patients (6-8). The efficacy of EGFRTKIs is associated with Asian race, shows gender specificity to women, non-smokers and adenocarcinoma histology (9). Furthermore, an association between mutations in the EGFR TK domain and sensitivity to EGFR-TKIs has been previously reported $(6,10)$.

EGFR mutations are located in EGFR exons 18 to 21 (9) and most mutations are observed as in-frame deletions in exon 19 and a point mutation L858R in exon 21 (11). Thus, testing for EGFR mutations may be prognostically important to identify potential responders who would benefit from treatment with EGFR-TKIs. This is particularly true for Chinese NSCLC patients with high EGFR mutation rates (12). The samples used for $E G F R$ mutations are usually from resected tumor tissues, which could be stably and easily detected. It is difficult to obtain sufficient tumor tissues with advanced NSCLC, thus alternative specimens need to be established for testing $E G F R$ mutations.

Malignant pleural effusion is a common complication of lung cancer. It is present in $\sim 15 \%$ of lung cancer patients and in 
$\sim 10-50 \%$ of patients at the time of diagnosis (13). In about half of NSCLC patients with a pleural effusion, most effusions are determined to be malignant consistent with the progress of the disease. As sampling of pleural effusion fluid is usually a standard and uncomplicated procedure, which is also non-invasive and repeatable, we hypothesized that genetic alterations in the pleural effusion fluid of NSCLC patients could provide useful guidelines with regard the response to EGFR-TKIs therapy.

In the present study, we used two approaches to detect major EGFR mutations in malignant pleural effusions from 24 patients presenting with advanced NSCLC and compared the acquired results. The relationship between $E G F R$ mutations with the efficacy of gefitinib was also evaluated.

\section{Patients and methods}

Patients. Cytologically or pathologically confirmed pleural effusions were obtained from 24 Chinese patients presenting with advanced NSCLC. Jinan General Hospital of PLA approved this study, and written informed consent was obtained from all participants. Eligibility criteria included patients with stage IIIB-IV, ECOG performance status (PS) of 0-3, and a life expectancy of at least 3 months. The records of all patients consisted of age, gender, smoking habit, histological type of NSCLC and treatment. The response of the patients to treatment with gefitinib was evaluated in accordance with the 'Response Evaluation Criteria in Solid Tumors (RECIST)' guidelines (14). No research results were entered into the records of any of the patients whatsoever or released to the patient or the physician of the patient. Each specimen was only labeled by a serial number without any identification.

Collection of pleural effusion fluid and DNA extraction. Pleural effusion fluid was collected from patients in heparinized tubes between 20th February and 22nd June 2012. No particular collection method was used. A $30 \mathrm{ml}$ volume sample of the fluid was centrifuged at $250 \mathrm{xg}$ for $10 \mathrm{~min}$ at room temperature, and the cell pellets were stored at $-80^{\circ} \mathrm{C}$ until used. Genomic DNA in the cell pellets was extracted by DNeasy tissue kits (Qiagen, Germany), and according to the manufacturer's protocol. The concentration and purity of extracted DNA were assessed by spectrophotometry (Nanodrop, ADx, China).

Polymerase chain reaction amplification and direct sequencing. Exons 19, 20 and 21 of the EGFR gene were amplified by polymerase chain reaction (PCR). The primers specific for $E G F R$ were designed using Primer Designer Software (primer premier 5.0). The sequences of primers for $E G F R$ exon 19 to 21 are described in Table I. Each $50 \mu 1$ reaction specimen contained $2 \mu \mathrm{l}$ of template DNA, $0.25 \mu \mathrm{l}$ of Ampli Taq Gold DNA polymerace (Roche, USA), $5 \mu \mathrm{l}$ of 10X PCR buffer, and $10 \mu \mathrm{M}$ of forward and reverse primer. The same PCR program was used for all amplicons: $95^{\circ} \mathrm{C}$ for $3 \mathrm{~min} ; 32$ cycles of $95^{\circ} \mathrm{C}$ for $30 \mathrm{sec}$, $55^{\circ} \mathrm{C}$ for $30 \mathrm{sec}, 72^{\circ} \mathrm{C}$ for $30 \mathrm{sec} ; 72^{\circ} \mathrm{C}$ for $10 \mathrm{~min}$. After PCR assay had completed, the resultant amplicons were further purified by QIAquick PCR purification kit (Qiagen), and subjected to sequencing analysis in both sense and antisense directions.

ADx-ARMS for the detection of EGFR mutations. We used an EGFR Gene 4 Mutations Diagnostic kit (ADx, Xiamen,

\section{a Exon 19 mutation}
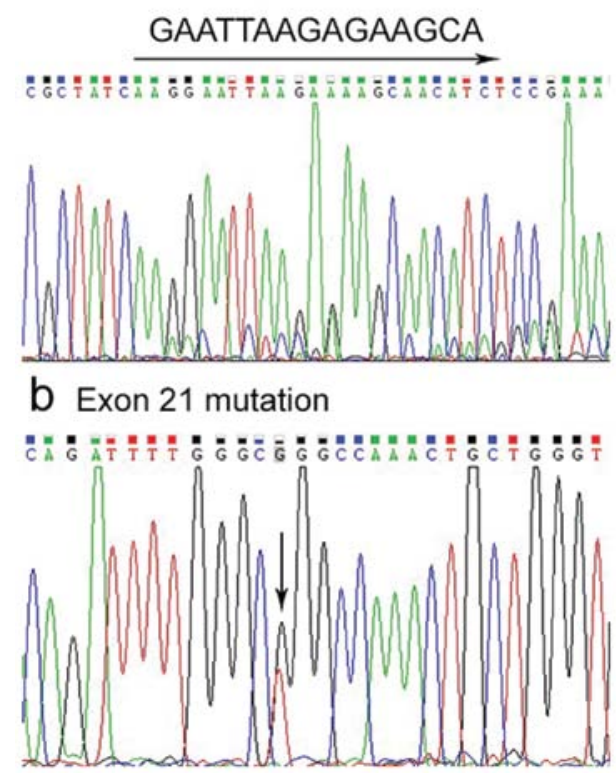

Figure 1. EGFR mutations as detected by direct gene sequencing. (a) Deletion mutation (delK744-A750, as indicated by the arrow) of exon 19. (b) Point mutation L858R ( $\mathrm{T} \rightarrow \mathrm{G}$, as indicated by the arrow) of exon 21 .

China), which combines the two technologies of ARMS and Bi-loop Probe, to detect mutations in real-time PCR reactions. All reactions proceeded in $25 \mu 1$ volumes according to the manufacturer's protocol. Real-time PCR was performed using the Mx3000P $\mathrm{P}^{\mathrm{TM}}$ real-time PCR system (Agilent, Germany) under the following conditions: initial denaturation at $95^{\circ} \mathrm{C}$ for $5 \mathrm{~min}, 15$ cycles of $95^{\circ} \mathrm{C}$ for $25 \mathrm{sec}, 64^{\circ} \mathrm{C}$ for $20 \mathrm{sec}, 72^{\circ} \mathrm{C}$ for $20 \mathrm{sec}$, and $31 \mathrm{cycles}$ of $95^{\circ} \mathrm{C}$ for $25 \mathrm{sec}, 60^{\circ} \mathrm{C}$ for $35 \mathrm{sec}$ (with fluorescence collection, set to FAM and HEX), and finally $72^{\circ} \mathrm{C}$ for $20 \mathrm{sec}$. Data were analyzed using Stratagene Mxpro software. The threshold cycle $(\mathrm{Ct})$ was defined as the cycle at the highest peak of the curve, which represents the point of maximum curvature of the growth curve. Positive results were defined as $\mathrm{Ct}<26$. Analysis of each sample was carried out in duplicate, and the whole test process required only $90 \mathrm{~min}$. The EGFR mutation kit is intended for detection of the major somatic mutations in EGFR.

Statistical analysis. SPSS statistical software (version 13.0) was used for statistical analysis. The Chi-square test was used to compare the sensitivity between direct sequencing and ADx-ARMS. Two-sided P-values of $<0.05$ were considered statistically significant.

\section{Results}

Patients. Sixteen male and 8 female patients were enrolled for the study. The median age was 58 years. Fourteen patients had no history of cigarette smoking; the ten current smokers were all male (Table).

Results of direct sequencing analysis. EGFR mutations were observed in 10 samples by direct sequencing of DNA, 4 deletions in exon 19, and 6 L858R mutations in exon 21 (Fig. 1). We did not detect any mutations in exon 20 (data not shown). 
Table I. Primers used for EGFR mutation screening by direct sequencing.

$\begin{array}{ll}\text { Exon } 19 & \text { CCAGCAATATCAGCCTTAGGTG } \\ \text { Exon } 20 & \text { GTCACTTCACAGCCCTGCGTA } \\ \text { Exon } 21 & \text { CTTGGAGGACCGTCGCTTG }\end{array}$

GGGGAGGGAGTTATACCCACTA

GTCACTTCACAGCCCTGCGTA

GAGAGACTGAAACCTAACATTTGCTA
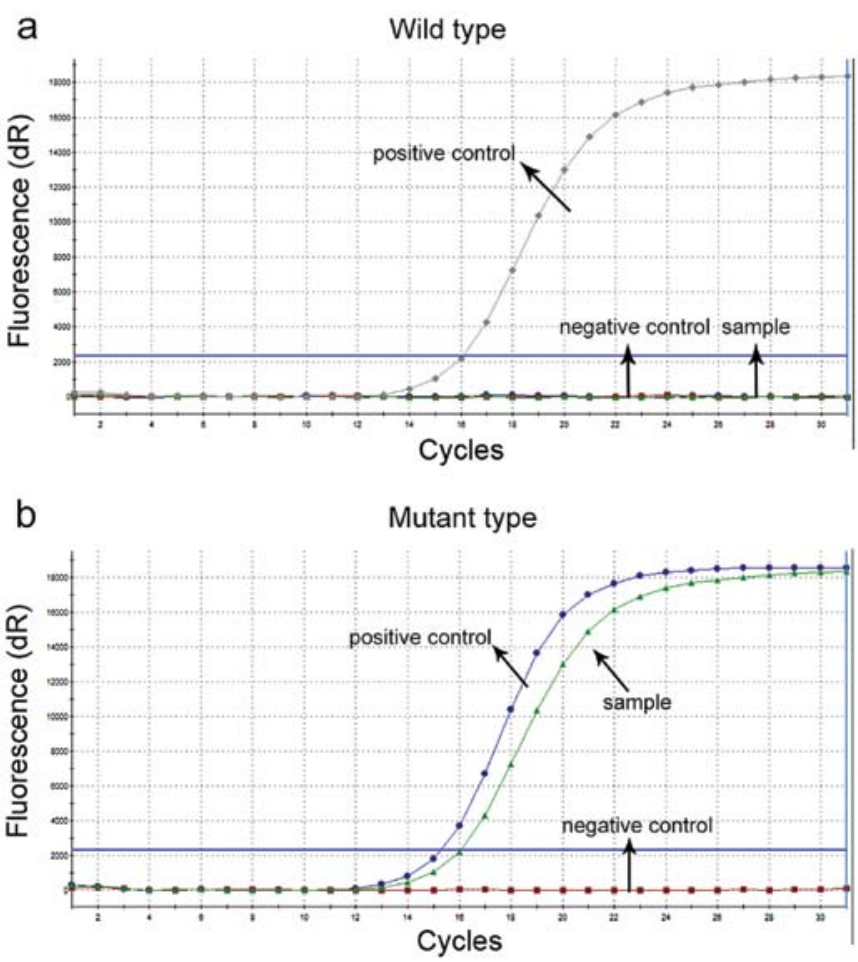

Figure 2. Curves of EGFR exon 19 using the ADx-ARMS method. (a) Only one curve indicating the positive control had increased. Thus, the sample was considered wild-type. (b) Curves for both positive control and mutanttype have increased. Thus, this sample was considered mutant-type. The blue curve represents the positive control, while the green curve was the deletion of exon 19.

ADx-ARMS analysis. ADx-ARMS analysis of EGFR mutations are shown in Fig. 2. The wild-type showed one increased curve, which was the positive control, and the mutant type showed two increased curves, which were the mutant and positive control curves, respectively. Using the EGFR Mutations Diagnostic kit, 6 deletion mutations in exon 19, and 8 L858R mutations in exon 21 of EGFR were detected. We confirmed that there was no mutation in exon 20 (not shown).

Comparison between direct sequencing and ADx-ARMS. We found gene mutations in EGFR in only 10 patients by the direct sequencing assay. Thus, direct gene sequencing was less sensitive than ADx-ARMS analysis. In 24 patients, EGFR mutations were detected in 14 samples $(58.3 \%)$ by ADx-ARMS, while 10 mutations (41.7\%) were detected by direct sequencing. However, no significant difference was seen between these approaches $\left(\chi^{2}=1.333, \mathrm{P}=0.248\right)$. Among the test results of 24 patients, there was an $83.3 \%$ concordance between direct sequencing and ADx-ARMS. Four EGFR a

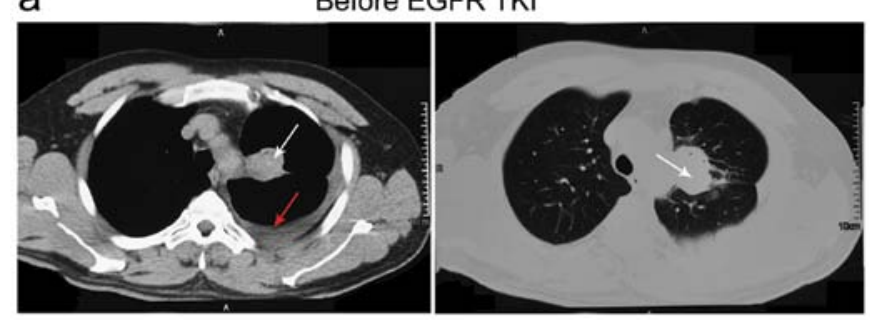

b

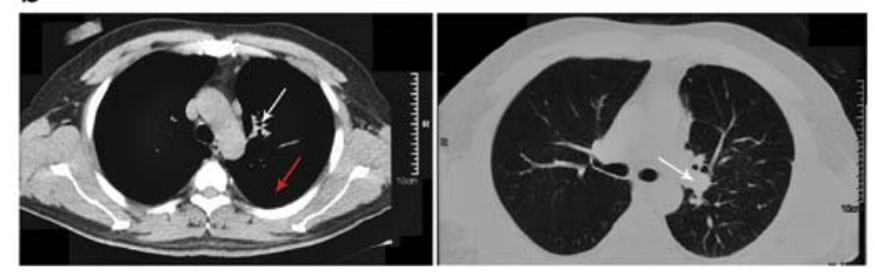

Figure 3. CT scan: representative response to EGFR TKIs for one patient (case no. 7: male, 51-year-old) carrying an EGFR L858R mutation detected only by the ADx-ARMS method (a) prior to gefitinib therapy; (b) 1 month post-therapy (pleural effusion seen by red arrows; tumor size seen by white arrows).

mutation-negative samples found by direct sequencing were mutation-positive by ADx-ARMS.

Correlation between EGFR mutation and clinical response. For patients treated with gefitinib, EGFR mutations were detected in cells from malignant pleural effusions in ten of the 18 patients (Table III). Among those 10 EGFR mutant samples, 8 patients achieved partial response, and 2 presented with stable disease after 28 days of gefitinib therapy. In the 8 patients who partially responded, 6 of them showed decreased levels of pleural effusion, and reduced size of the tumor (Fig. 3). Six of the eight patients who had no demonstrable EGFR mutations progressed to develop the disease. While defining a patient with partial response as a responder, the frequency of $E G F R$ mutations was significantly higher in gefitinib responders $(8 / 9)$ than was found in non-responders $(2 / 9, \mathrm{P}=0.02)$.

\section{Discussion}

In this study, we demonstrated the feasibility of using DNA from malignant pleural effusion as an alternative to tumor samples for the detection of EGFR mutations from advanced NSCLC patients.

We used the pleural effusion samples to detect EGFR mutation status and compared two methods: i) gene sequencing and, ii) ADx-ARMS. We also showed that patients with mutant EGFR had a better response to treatment with EGFR-TKIs. 
Table II. Clinical characteristics and demographics of the patients.

\begin{tabular}{lcc}
\hline Variables & $\begin{array}{c}\text { No. of patients } \\
(\mathrm{n}=24)\end{array}$ & $\begin{array}{c}\text { Percentage of } \\
\text { patients }\end{array}$ \\
\hline Age (years) & & \\
Median & 64 (range: $49-84)$ & \\
$\leq 70$ & 14 & 58.3 \\
$>70$ & 10 & 41.7 \\
Gender & & \\
Male & 16 & 66.7 \\
Female & 8 & 33.3 \\
Smoking habit & & \\
Never-smoker & 8 & 33.3 \\
Current or former smoker & 16 & 66.7 \\
Pathology & & \\
Adenocarcinoma & 20 & 16.7 \\
Non-adenocarcinoma & 4 & 25 \\
Chemotherapy & & 75 \\
Chemotherapy naïve & 6 & \\
Previous chemotherapy & 18 & \\
\hline & & \\
\hline
\end{tabular}

In our study, the response rate was $80 \%$ (8 of 10 patients achieved partial response) in EGFR mutation patients, while $E G F R$ wild-type patients had only a $12.5 \%$ response rate (1 of 8 patients achieved partial response). Patients with mutant $E G F R$, had a response rate which was significantly higher than patients with wild-type $E G F R(\mathrm{P}<0.05)$. The data are in agreement to other previously reported studies (15-17).

Direct gene sequencing has been regarded as a gold-standard method for gene mutation analysis in the last decades. Direct sequencing usually requires sufficient tumor tissue as the testing sample with a sensitivity of $\sim 30 \%(18,19)$. However, it is challenging to obtain sufficient tissue for gene sequencing in advanced NSCLC. In addition, gene sequencing is both time-consuming and technically demanding (17). Many studies have shown that gene sequencing is unable to provide satisfactory data for the detection of pleural effusion fluid samples that contain mixtures of DNA from normal cells $(20,21)$, thus it cannot be widely used in clinical practice. Therefore, alternative clinical samples with more sensitive methodological approaches are urgently needed for individualized therapy of EGFR-TKIs.

Pleural effusion fluid, which has DNA from tumor cell pellets or the free DNA from the tumor provide a good alternative $(17,20,22)$. The advantage of collecting free DNA or cell pellets is that it is a relatively simple approach, it is non-invasive and a repeatable technique. Thus, it could dynamically guide clinical approaches. Due to different methods and the selectivity of lung cancer patients with pleural effusion fluid, the frequency of mutant EGFR is in the range of $12.5-73 \%(17,20,21,23-25)$.

In our study, the frequency of EGFR mutations (deletion mutations and L858R mutations) detected by sequencing and
Table III. EGFR mutations and the response treated with gefitinib in 18 patients.

\begin{tabular}{rcccc}
\hline No. of patients & Response & Gender & $\begin{array}{c}\text { Age } \\
\text { (yrs.) }\end{array}$ & $\begin{array}{c}\text { EGFR } \\
\text { mutation }\end{array}$ \\
\hline 1 & PR & F & 61 & Exon 21 \\
22 & PR & F & 49 & Exon 21 \\
5 & SD & M & 77 & Exon 19 \\
16 & PR & M & 84 & Exon 19 \\
7 & PR & M & 51 & Exon 21 \\
8 & PR & F & 59 & Exon 19 \\
11 & PR & F & 65 & Exon 21 \\
2 & PR & M & 81 & Exon 19 \\
9 & PR & M & 73 & Exon 21 \\
3 & SD & M & 51 & Exon 21 \\
14 & PD & M & 63 & WT \\
17 & PD & M & 49 & WT \\
19 & SD & F & 52 & WT \\
24 & PD & F & 73 & WT \\
20 & PD & F & 61 & WT \\
23 & PD & M & 73 & WT \\
12 & PR & M & 61 & WT \\
4 & PD & M & 55 & WT \\
\hline
\end{tabular}

M, male; F, female; WT, wild-type; PR, partial response; SD, stable disease; $\mathrm{PD}$, progressive disease.

by ADx-ARMS was found to be $41.7 \%$ and $58.3 \%$, respectively. ADx-ARMS appeared to be the more sensitive approach as compared with direct sequencing in this study. The mutations detected by ADx-ARMS consisted of an in-frame deletion in exon 19 (E746_A750 del: 2235_2249del15 and 2236_2250del15), an insertion mutation in exon 20 (T790M), and a point mutation in exon 21 (L858R). Other deletion patterns in exon 19 and other mutations in the tyrosine kinase domain of EGFR could not be detected by this assay.

Among the 24 patients, there was $83.3 \%$ concordance between direct sequencing and ADx-ARMS. Our findings of a correlation between $E G F R$ mutations and tumor response to therapy with TKIs was consistent with previous studies $(15,16)$. Due to the small number of our samples, the EGFR mutation rate showed no significant difference between these two methods $\left(\chi^{2}=1.333, \mathrm{P}=0.248\right)$. At this point, it is worthwhile mentioning two limitations of our study. One is that we did not compare EGFR mutations between effusion cells and primary tumors, the main reason being that some tumor samples were not available. In addition, our results need further study based on the relationship between EGFR mutations and progressivefree survival and overall survival.

In summary, the clinical responses of NSCLC to EGFRtargeted therapy are closely associated with $E G F R$ sensitive mutations. Screening of EGFR mutations by the ADx-ARMS approach using malignant pleural effusion as the source specimen is more sensitive and faster as compared with traditional gene sequencing approaches. These observations support 
the utility of this technology in routine clinical practice, an approach that can benefit patients presenting with advanced NSCLC.

\section{References}

1. No authors listed: Chemotherapy in non-small cell lung cancer: a meta-analysis using updated data on individual patients from 52 randomised clinical trials. Non-small Cell Lung Cancer Collaborative Group. BMJ 311: 899-909, 1995.

2. Haura EB: Treatment of advanced non-small-cell lung cancer: a review of current randomized clinical trials and an examination of emerging therapies. Cancer Control 8: 326-336, 2001.

3. Schiller JH: Current standards of care in small-cell and nonsmall-cell lung cancer. Oncology 61 (Suppl 1): 3-13, 2001.

4. Ohsaki Y, Tanno S, Fujita Y, et al: Epidermal growth factor receptor expression correlates with poor prognosis in non-small cell lung cancer patients with p53 overexpression. Oncol Rep 7: 603-607, 2000

5. Nicholson RI, Gee JM and Harper ME: EGFR and cancer prognosis. Eur J Cancer 37 (Suppl 4): 9-15, 2001.

6. Lynch TJ, Bell DW, Sordella R, et al: Activating mutations in the epidermal growth factor receptor underlying responsiveness of non-small-cell lung cancer to gefitinib. N Engl J Med 350: 2129-2139, 2004.

7. Paez JG, Janne PA, Lee JC, et al: EGFR mutations in lung cancer: correlation with clinical response to gefitinib therapy. Science 304: 1497-1500, 2004.

8. Han SW, Kim TY, Hwang PG, et al: Predictive and prognostic impact of epidermal growth factor receptor mutation in nonsmall-cell lung cancer patients treated with gefitinib. J Clin Oncol 23: 2493-2501, 2005.

9. Shigematsu H, Lin L, Takahashi T, et al: Clinical and biological features associated with epidermal growth factor receptor gene mutations in lung cancers. J Natl Cancer Inst 97: 339-346, 2005.

10. Carey KD, Garton AJ, Romero MS, et al: Kinetic analysis of epidermal growth factor receptor somatic mutant proteins shows increased sensitivity to the epidermal growth factor receptor tyrosine kinase inhibitor, erlotinib. Cancer Res 66: 8163-8171, 2006.

11. Borras E, Jurado I, Hernan I, Gamundi MJ, Dias M, Marti I, Mane B, Arcusa A, Agundez JA, Blanca M and Carballo M: Clinical pharmacogenomic testing of KRAS, BRAF and EGFR mutations by high resolution melting analysis and ultra-deep pyrosequencing. BMC Cancer 11: 406, 2011.

12. Zhou C, Wu YL, Chen G, et al: Erlotinib versus chemotherapy as first-line treatment for patients with advanced EGFR mutationpositive non-small-cell lung cancer (OPTIMAL, CTONG-0802): a multicentre, open-label, randomised, phase 3 study. Lancet Oncol 12: 735-742, 2011
13. Fenton KN and Richardson JD: Diagnosis and management of malignant pleural effusions. Am J Surg 170: 69-74, 1995.

14. Therasse P, Arbuck SG, Eisenhauer EA, et al: New guidelines to evaluate the response to treatment in solid tumors. European Organization for Research and Treatment of Cancer, National Cancer Institute of the United States, National Cancer Institute of Canada. J Natl Cancer Inst 92: 205-216, 2000.

15. Giaccone G, Herbst RS, Manegold C, et al: Gefitinib in combination with gemcitabine and cisplatin in advanced non-small-cell lung cancer: a phase III trial - INTACT 1. J Clin Oncol 22: 777-784, 2004.

16. Herbst RS, Giaccone G, Schiller JH, et al: Gefitinib in combination with paclitaxel and carboplatin in advanced non-small-cell lung cancer: a phase III trial - INTACT 2. J Clin Oncol 22: 785-794, 2004.

17. Jian G, Songwen Z, Ling Z, et al: Prediction of epidermal growth factor receptor mutations in the plasma/pleural effusion to efficacy of gefitinib treatment in advanced non-small cell lung cancer. J Cancer Res Clin Oncol 136: 1341-1347, 2010.

18. Bosari S, Marchetti A, Buttitta F, et al: Detection of p53 mutations by single-strand conformation polymorphisms (SSCP) gel electrophoresis. A comparative study of radioactive and nonradioactive silver-stained SSCP analysis. Diagn Mol Pathol 4: 249-255, 1995

19. Fan X,Furnari FB, Cavenee WK, et al: Non-isotopic silver-stained SSCP is more sensitive than automated direct sequencing for the detection of PTEN mutations in a mixture of DNA extracted from normal and tumor cells. Int J Oncol 18: 1023-1026, 2001.

20. Kimura H, Fujiwara Y, Sone T, et al: EGFR mutation status in tumour-derived DNA from pleural effusion fluid is a practical basis for predicting the response to gefitinib. Br J Cancer 95: 1390-1395, 2006.

21. Kimura H,Kasahara K, Kawaishi M, et al: Detection of epidermal growth factor receptor mutations in serum as a predictor of the response to gefitinib in patients with non-small-cell lung cancer. Clin Cancer Res 12: 3915-3921, 2006.

22. Kubo A, Koh Y, Kawaguchi T, et al: Malignant pleural effusion from lung adenocarcinoma treated by gefitinib. Intern Med 50: 745-748, 2011.

23. Zhang X, Zhao Y, Wang M, et al: Detection and comparison of epidermal growth factor receptor mutations in cells and fluid of malignant pleural effusion in non-small cell lung cancer. Lung Cancer 60: 175-182, 2008.

24. Han HS, Lim SN, An JY, et al: Detection of EGFR mutation status in lung adenocarcinoma specimens with different proportions of tumor cells using two methods of differential sensitivity. J Thorac Oncol 7: 355-364, 2012.

25. Tsai TH, Wu SG, Chang YL, et al: Effusion immunocytochemistry as an alternative approach for the selection of first-line targeted therapy in advanced lung adenocarcinoma. J Thorac Oncol 7: 993-1000, 2012. 